\title{
Avaliação da resistência à tração de artifícios ortodônticos - braquete, botão e tela - colados em pré-molares com resina autopolimerizável. Estudo "in vitro"
}

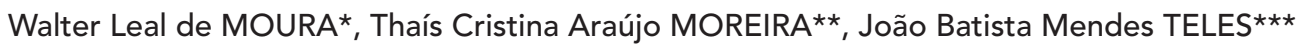

\begin{abstract}
Resumo
Retenção dentária é a condição fisiopatológica em que o dente, uma vez chegado o seu momento fisiológico de erupção, apresenta algum impedimento para realizá-lo. O tratamento, com envolvimento cirúrgico-ortodôntico, visa deslocar o elemento dental para a correta posição na arcada dentária, sem causar danos aos elementos dentais adjacentes, restabelecendo a estética e a função. A colagem direta de botões e braquetes ortodônticos para tração de dentes inclusos transformou-se na técnica preferida, pois exige menor extensão cirúrgica e remoção de tecido para acesso à coroa dental. A pesquisa objetivou analisar a intensidade da força aplicada ao conjunto dente/artifício/fio de amarrilho, pelo tracionamento, e observar o local do rompimento. Utilizaram-se 45 pré-molares, conservados em soro fisiológico 0,9\%, que foram divididos em 3 grupos (15 com braquetes, 15 com botões e 15 com telas). Os dentes foram fixados em canos de PVC preenchidos com resina acrílica e os acessórios fixados ao dente com resina autopolimerizável. Após a colagem dos acessórios ortodônticos, os dentes voltaram a ser conservados em soro fisiológico e o teste realizado após 72 horas, com a utilização de um sensor de força e um programa de computador (Logger Pro). Com os resultados, observou-se que o braquete resistiu a uma força média de $36,0 \mathrm{~N}$, sendo a junção fio/braquete o local menos resistente; o botão resistiu a uma força média de $41,2 \mathrm{~N}$, a junção fio/botão ortodôntico foi o local menos resistente e a tela resistiu a uma força média de $28,8 \mathrm{~N}$, sendo a junção dente/tela o local menos resistente.
\end{abstract}

Palavras-chave: Tracionamento. Impacção. Canino incluso.

\section{INTRODUÇÃO}

Entende-se por erupção dentária, todo movimento fisiológico do dente em direção ao plano oclusal, desde passos intra-alveolares até movi- mentos compensatórios, provocados por desgaste oclusal. O conhecimento acerca desse fenômeno, ainda hoje, reveste-se de indagações, havendo inúmeras hipóteses acadêmicas que tentam explicá-la.

\footnotetext{
* Professor Ajunto IV e Coordenador da disciplina de Cirurgia e Traumatologia Bucomaxilofacial da UFPI, Doutor em Odontologia - CTBMFacial pela FoAraçatuba-UNESP, Membro Titular do Colégio Brasileiro de CTBMFacial.

** Aluna do Curso de Odontologia da Universidade Federal do Piauí. Bolsista do CNPq.

*** Prof. Adjunto IV e Coordenador da disciplina de Bioestatística da Universidade Federal do Piauí.
} 
Porém, é certa a existência de uma forte regência genética neste processo, com participação de fatores do meio-ambiente ${ }^{13}$.

O termo retenção dentária significa que um dente no momento fisiológico de erupção, apresenta algum impedimento para realizá-1o ${ }^{8}$. A inclusão dental é um problema clínico-cirúrgico importante, dado à freqüência com que ocorre e às suas conseqüências locais ${ }^{11}$.

A falta de espaço no arco dental parece ser o principal fator etiológico das inclusões dentais, pois os últimos dentes a fazerem erupção, geralmente, são os mais acometidos. Dentre os dentes mais freqüentemente inclusos estão os terceiros molares inferiores e superiores e os caninos superiores ${ }^{5,11}$. Em relação aos caninos, essa assertiva justifica-se pelo fato deles se desenvolverem em uma posição alta no processo alveolar, acima de todos os outros dentes em formação. Assim, descrevem um trajeto de irrupção mais longo e duradouro, que os torna mais susceptiveis a fatores etiológicos diversos e uma trajetória ectópica de irrupção ${ }^{6}$.

Comentando sobre a etiologia das impactações dentárias, Moyers ${ }^{9}$ citou que as causas podem ser primárias e secundárias. Enumerou como causas primárias: 1) reabsorção radicular do dente decíduo; 2) trauma dos germes dos dentes decíduos; 3) disponibilidade de espaço no arco; 4) rotação dos germes dos dentes permanentes; 5) fechamento prematuro dos ápices radiculares; 6) irrupção de caninos em áreas de fissuras palatinas; e como causas secundárias: 1) pressão muscular anormal; 2) doenças febris; 3) distúrbios endócrinos e 4) deficiência de vitamina $\mathrm{D}^{2}$.

O diagnóstico é realizado através de minucioso exame clínico-radiográfico ${ }^{5}$. No estágio de dentadura permanente, a avaliação clínica é um indício conclusivo. A ausência clínica do dente sugere inclusão. A inspeção clínica mediante a palpação da região vestibular e palatina pode ajudar no diagnóstico de localização ${ }^{12}$. Os sinais clínicos de dente impactado incluem retenção do dente decíduo, espaço diminuído e elevação do tecido mole do palato ou da mucosa labial dependendo da localização do dente impactado 5 .

O diagnóstico radiográfico pode ser feito durante exames de rotina e a localização de dente incluso, descoberta usando várias técnicas como radiografias panorâmicas, oclusais, periapicais e técnica de Clark ${ }^{5}$. As radiografias periapicais dão uma boa indicação da localização labial-palatal do canino em relação ao incisivo, como na técnica de Clark. A técnica oclusal é a melhor por determinar a posição do canino em relação à linha média. Superposição de estruturas pode tornar difícil a interpretação dessa radiografia. O cefalograma lateral revela a posição ântero-posterior, inclinação e localização vertical do canino. A radiografia panorâmica em conjunto com a periapical, ou a radiografia maxilar oblíqua é o método preferível de localização de canino impactado ${ }^{3}$.

São exemplos de complicações que podem ser descobertas radiograficamente: possibilidade de erupção ectópica, reabsorção de dentes adjacentes, lesões (císticas ou tumorais) associadas ao folículo ${ }^{1}$.

Uma vez decidido pela intervenção terapêutica, deve-se optar por um planejamento coerente entre levar o dente até sua correta posição no arco dentário ou extraí-lo ${ }^{12}$.

A extração do dente incluso com ou sem a preservação do decíduo deve ocorrer somente nos casos em que a utilização de métodos conservadores não é possível. Dentes em posição horizontal, presença de anquilose alvéolo-dentária, grande dilaceração apical, insuficiência de espaço entre outros, são exemplos de prognóstico à conduta conservadora ${ }^{10}$.

Vários autores têm utilizado o método do transplante, alguns relatando sucesso; mas outros casos com anquilose e reabsorção externa. Quanto menos tempo o dente permanecer fora do alvéolo e quanto menos for manipulado, mais favorável é o prognóstico. Dentes com ápices abertos também apresentam melhor prognóstico comparados com aqueles que têm formação radicular completa. Este método é indicado como uma alternativa viável para casos como ausência congênita, perda traumática dos dentes ou impacções severas ${ }^{4}$. 
A opção pelo reposicionamento oclusal de dentes permanentes impactados pode ser planejada obedecendo duas linhas terapêuticas: intervenção cirúrgica isolada e intervenção cirúrgico-ortodôntica ${ }^{12}$.

Sem dúvida alguma, a filosofia de tratamento mais usada atualmente requer um envolvimento cirúrgico-ortodôntico. Nessa abordagem a cirurgia assume a técnica de abrir o espaço necessário para a adaptação imediata de um dispositivo que receberá a força ortodôntica ${ }^{12}$.

A colagem direta de telas, botões e braquetes ortodônticos para tração de dentes inclusos transformou-se na técnica preferida para o tracionamento pois, além da maior facilidade, exige menor extensão cirúrgica e remoção de tecido para acesso à coroa dental do que as outras técnicas ${ }^{7,8}$. Dentre estes artifícios empregados para esta técnica, os de utilização mais comum são os braquetes, telas e botões montados com um ou dois fios de amarrilho de 0,10 a 0,12 polegadas. Não há um consenso entre os autores sobre qual artifício ortodôntico é mais vantajoso. Alguns autores relatam ser melhor o uso das telas por possuírem menor volume, facilitando mais a movimentação do dente ${ }^{7}$. Além disso, de acordo com Nogueira et al. ${ }^{10}$ as telas apresentam mais vantagens por possuírem pouca espessura se comparadas aos demais dispositivos, aspecto muito importante quando da recolocação do retalho em sua posição de origem, pois as telas não agiriam como fator irritante, eliminando o risco de ocorrer um processo inflamatório de origem traumática. Entretanto, uma dúvida ainda persiste: qual seria o dispositivo mais resistente ao deslocamento da superfície dental?

Apesar de ser amplamente difundida, a exposição cirúrgica do dente incluso e colagem de artifícios ortodônticos na coroa apresenta algumas desvantagens e contra-indicações e, dependendo do posicionamento do dente, a técnica se torna inviável, além da dificuldade para execução de perfeito condicionamento ácido do esmalte 7 . Isto ocorre quando o dente encontra-se muito alto, tornando difícil a colagem e facilitando a perda do acessório durante o procedimento ortodôntico de tracionamento, requerendo, assim, nova cirurgia ${ }^{12}$. Fazendo-se um isolamento da coroa dentária com gaze, exercendo pressão sobre os tecidos adjacentes, consegue-se conter o sangramento ou ainda, quando excessivo, pode-se lançar mão do uso de hemostáticos tópicos para diminuí-lo ${ }^{8,10}$.

Assim como em toda técnica para tratamento de dentes inclusos, o tracionamento também tem suas desvantagens, como: anquilose, descoloração, desvitalização, reabsorção radicular do incluso ou dos dentes adjacentes, recessão gengival e deficiência da gengiva inserida, devendo o paciente estar ciente dos mesmos. A má seleção dos casos, normalmente, é a causa primária do insucesso ${ }^{10}$.

\section{MATERIAIS E MÉTODOS}

Neste trabalho foram utilizados 45 pré-molares, extraídos com finalidade ortodôntica, conservados em soro fisiológico a 0,9\% (Glicolabor - Indústria Farmacêutica). Após a extração os pacientes foram esclarecidos com relação ao uso dos elementos dentários na pesquisa e assinaram um "termo de consentimento" autorizando a utilização dos mesmos. Os elementos dentários foram divididos em três grupos de 15 dentes, onde em cada grupo foi testado um tipo de acessório utilizado clinicamente na realização de tracionamento cirúrgico-ortodôntico: braquete, botão e tela. As raízes dos dentes foram incluídas em dispositivos específicos (cano de PVC com diâmetro e tamanho padronizados, preenchidos com resina acrílica - Dentsply Indústria e Comércio Ltda.) para realização dos testes de tração. Estes acessórios foram fixados aos dentes com resina autopolimerizável (Oncise - 3M). Para colagem dos acessórios ortodônticos foi feito condicionamento com ácido fosfórico a 37\% durante 1 minuto na superfície dentária, lavagem com água destilada e secagem com jato de ar. Em seguida foi aplicado com um pincel, à superfície de esmalte condicionada, a mistura de uma gota da resina fluída catalisadora e uma gota da resina fluída universal. As pastas universal e catalisadora foram dosadas na proporção de 1/1 e misturadas durante 15 segundos até aglutinação uniforme e aplicadas ao dente com espátula plástica. 
Após a realização de colagem dos acessórios ortodônticos, os dentes foram conservados em soro fisiológico $0,9 \%$. Os testes foram realizados 72 horas após a colagem através da utilização de um programa de computador (Logger Pro).

O dente fixo no dispositivo (cano de PVC + resina acrílica) foi colocado em posição horizontal e ancorado a uma mesa por um grampo com garra para realização do teste de tração. O fio de amarrilho $0,20 \mathrm{~mm}$ que estava preso ao acessório ortodôntico (braquete, botão ou tela) foi fixado ao sensor de força por meio de uma garra existente em uma das extremidades do sensor, que por sua vez foi conectado ao computador através da interface (Fig. 1). Neste momento foi exercida uma força de tração pelo operador até que ocorresse o rompimento do fio de amarrilho (junção fio de amarrilho/acessório ou junção acessório/dente) ou descolagem do artifício. À medida em que era exercida a força de tração o computador registrava os valores que seriam exibidos em gráficos, demonstrando o momento exato do rompimento e portanto o final de sua resistência à tração.

As variáveis foram registradas em fichas desenhadas de modo a facilitar a entrada desses quesitos no computador através do programa SPSS 10.1, que fazia a elaboração dos dados. No levantamento estatístico utilizou-se a análise de variância (ANOVA) para verificar se as resistências medidas foram diferentes nas três técnicas utilizadas. Portanto, as estatísticas são as médias, desvio padrão e proporção, que fazem as descrições e inferências para o alcance dos objetivos.

\section{DISCUSSÃO}

Segundo Saad Neto e Carvalho ${ }^{11}$, Nogueira et al. ${ }^{10}$, Moraes et al. ${ }^{8}$ e Garib et al. ${ }^{6}$, o método mais utilizado para a realização do tracionamento é a colagem direta de artifícios ortodônticos. De acordo com os resultados obtidos em nosso trabalho, observou-se que o botão foi o melhor artifício ortodôntico para o tracionamento, uma vez que resistiu às maiores forças de tração em relação ao braquete e à tela.
Nogueira et al. ${ }^{10}$, deram preferência ao uso das telas por possuírem pouca espessura se comparadas aos demais dispositivos. Isso, tornando-se importante, pois, quando da recolocação da fibromucosa em sua posição de origem, a tela não age como fator irritante, eliminando o risco de ocorrer um processo inflamatório de origem traumática.

Para Saad Neto e Carvalho ${ }^{11}$, a colagem direta com tela ocupa menor volume sob o retalho mucoperiostal, diferente de quando se utiliza botões ou braquetes, além de não danificar a superfície da coroa, ocorrência observada noutros procedimentos. Permite movimentação livre do incluso e proporciona melhor adaptação e retenção mesmo com o emprego de pouca resina composta entre a tela e o dente. Em nosso trabalho, observamos que a tela foi o artifício que menos resistiu às forças de tração,

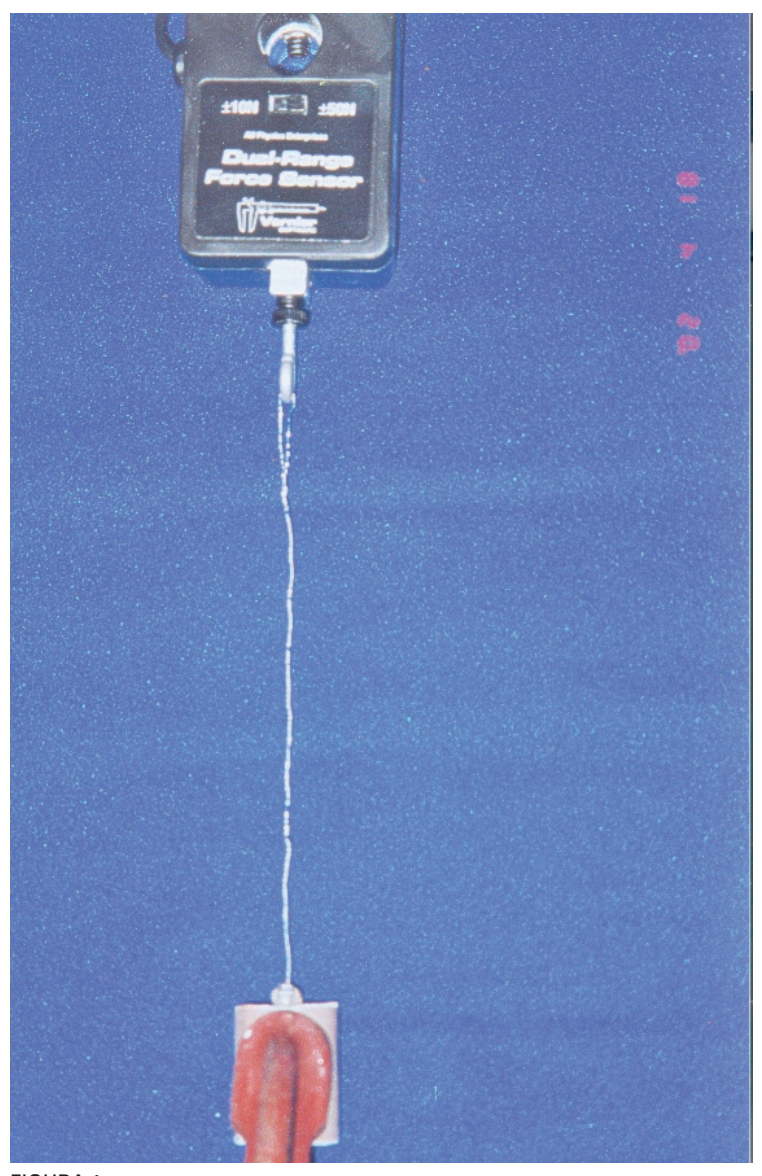

FIGURA 1 


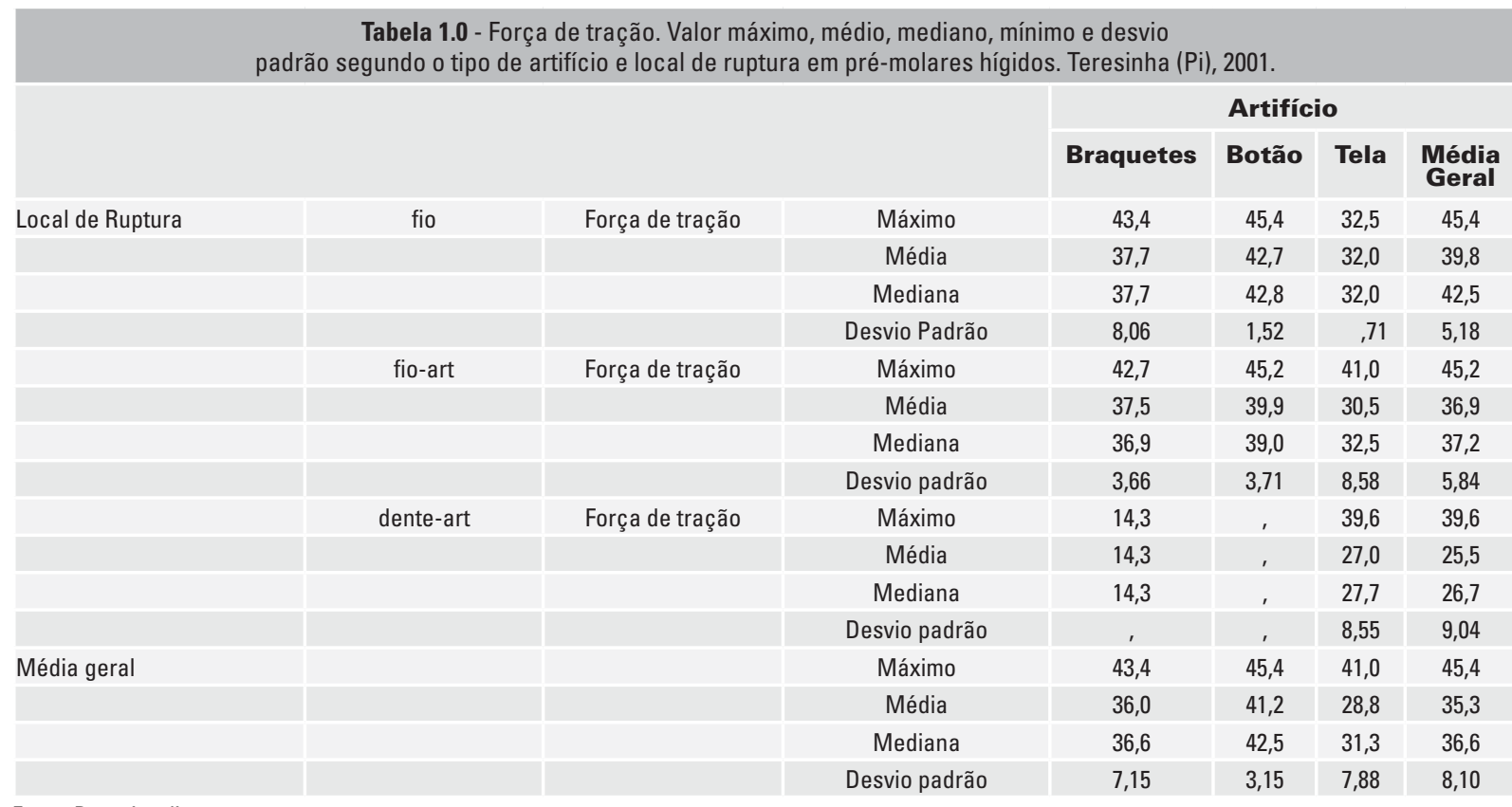

Fonte: Pesquisa direta

\begin{tabular}{|c|c|c|c|c|c|c|}
\hline & & & \multicolumn{3}{|c|}{ Local de Ruptura } & \multirow{2}{*}{ Total } \\
\hline & & & fio & fio-art & dente-art & \\
\hline \multirow[t]{6}{*}{ Artifício } & Braquetes & $n^{0}$ & 2 & 12 & 1 & 15 \\
\hline & & $\%$ & 13,33 & 80,00 & 6,67 & 100,00 \\
\hline & Botão & $\mathrm{n}^{0}$ & 7 & 8 & & 15 \\
\hline & & $\%$ & 46,67 & 53,33 & & 100,00 \\
\hline & Tela & $n^{0}$ & 2 & 5 & 8 & 15 \\
\hline & & $\%$ & 13,33 & 33,33 & 53,33 & 100,00 \\
\hline \multirow[t]{2}{*}{ Total } & & $\mathrm{n}^{0}$ & 11 & 25 & 9 & 45 \\
\hline & & $\%$ & 24,44 & 55,56 & 20,00 & 100,00 \\
\hline
\end{tabular}

Fonte: Pesquisa direta

tendo uma média geral de $28,8 \mathrm{~N}$, enquanto o botão resistiu a uma força média geral de $41,2 \mathrm{~N}$. A tela, além de ter resistido menos às forças, foi o artifício que mais descolou do dente $(53,33 \%$ dos casos). $\mathrm{O}$ fato da tela ter resistido menos às forças e ter descolado com maior facilidade não a contra indica para a realização de tracionamento cirúrgico-ortodôntico. Outros fatores devem ser considerados, como o grande volume dos botões que sob mucosa alveolar é contra indicado, devido ao traumatismo após o reposicionamento do retalho, como lembram Nogueira et al. ${ }^{10}$. Desta forma, os botões seriam indicados para área de gengiva inserida como no palato, enquanto a tela estaria indicada para as outras áreas.

\section{CONCLUSÕES}

A tela foi o artifício menos resistente, sendo a força média por ela suportada de $28,8 \mathrm{~N}$. O local menos resistente foi a junção dente-tela.

Em segundo lugar ficou o braquete, com uma força média de $36,0 \mathrm{~N}$, sendo o local menos resistente a junção fio-braquete.

O artifício mais resistente foi o botão ortodôntico, resistindo a uma força média de 41,2N. O local menos resistente foi a junção fio-botão.

Houve diferença significante entre as médias de tração entre os artifícios.

\section{AGRADECIMENTOS}

Ao professor Franklin de Oliveira Cruzio pelo auxílio na realização dos testes de tração e à professora Alessandra Tobias Braga pelo auxílio na documentação fotográfica. 


\title{
Evaluation of the resistance to traction of orthodontic devices - bracket, bouton and frame - bonded in premolar with autopolimerizable resin. "in vitro" study
}

\begin{abstract}
Restrained is the tooth which, reached its physiological moment of eruption, shows some obstruction to accomplish it. The treatment, with orthodontic-surgical involvement, type drives at to dislocate the dental element for right position in the dental arch, without to cause damages for adjacent dental element, re-establishing the aesthetics and function. Therefore, the direct bonding of orthodontic bracket and bouton for retained teeth traction became the preferred technic for, besides more clear, it demands smaller surgical amplitude and tissue removal to grant access to the dental crown. The research intended analyse the intensity of applied force to the entirety teeth/device/tie-wire, tractioning through, and to observe the splot rupture. Maked use of 45 premolar, conserved in $0.9 \%^{1}$ physiological serum, that was divided into three groups ( 15 with brackets, 15 with boutons and 15 with frames). The tooth was filled in PVC pipe filled with acrylic resin and the devices was bonded to the teeth with autopolimerizable resin. After the bonding realization of the orthodontic devices, the tooth was be preserved in physiological serum and the tests was be realized after 72 hours of the bonding by means of a computer program. The bracket endured to medium force of $36,0 \mathrm{~N}$, being the junction wiredevice the spot less resistant; the bouton endured to medium force of $41,2 \mathrm{~N}$, the juncion wire-bouton was the plot less resistant and the frame was endured to medium force of $28,8 \mathrm{~N}$, being the junction teeth/frame the plot less resistant.
\end{abstract}

Key words: Tractioning. Restrainment. Canine restrainmed.

\section{REFERÊNCIAS}

1. ALMEIDA, F. L. D. de et al. Caninos inclusos e impactados: abordagem ortocirúrgica. R Bras Odontol, Rio de Janeiro, p. 50-53, 1995.

2. ALMEIDA, R. R. et al. Abordagem da impactação e/ou irrupção ectópica dos caninos permanentes: considerações gerais, diagnóstico e terapêutica. R Dental Press Orthodon Ortop Facial, Maringá, v. 6, n. 1, p. 93-116, jan./fev. 2001.

3. CAMINITI, M. F. et al. Outcomes of the surgical exposure, bonding and eruption of 82 impacted maxillary canines. J Can Dent Assoc, Toronto, p. 572-574; 576-579, 1998.

4. CRUZ, M. ; SILVA,V. C. e. Movimentação cirúrgica de dentes inclusos: deslocamento controlado. Ortodontia, São Paulo, v. 27, n. 1, p. 39-51, jan./fev./mar./abr. 1994.

5. DUNCAN, W. K.; ASHRAFI, M. H. Management of the nonerupted maxillary anterior tooth. J Am Dent Assoc, Chicago, v.106, p. 640-644, May 1983.

6. GARIB, D. G. et al. Caninos superiores retidos: preceitos clínicos e radiográficos. $\mathbf{R}$ Dental Press Ortodon Ortop Facial, Maringá, v. 4, n. 4, p. 14-20, jul./ago. 1999.

7. KAYATT, F. E. et al. Tracionamento de dente incluso. RGO, Porto Alegre, v. 40, n. 2, p.140-142, mar./abr. 1992.
8. MORAES, M. de et al. Estudo comparativo entre procedimento de colagem do botão ortodôntico para tracionamento de dentes retidos. R Dental Press Ortodon Ortop Facial, Maringá, v. 3, n. 5, p. 52-58, set./out. 1998.

9. MOYERS, R. E. Etiologia das más oclusões. Ortodontia. 4. ed. Rio de Janeiro: Guanabara Koogan, 1991. p. 127-139.

10. NOGUEIRA, A. S. et al. Condutas cirúrgico-ortodônticas relacionadas aos caninos inclusos. Ortodontia, São Paulo, v. 30, n. 1, p. 84-92, jan./fev./mar./abr. 1977.

11. SAAD NETO, M. ; CARVALHO, A. C. P. Caninos inclusos I. Etiologia, incidência e tratamento. Rev Reg Araçatuba-Assoc Paul Cir Dent, Araçatuba, v. 4, n. 1, p.19-34, 1983.

12. SILVA FILHO, O. G. et al. Irrupção ectópica dos caninos permanentes superiores: soluções terapêuticas. Ortodontia, São Paulo, v. 27, n. 3, p. 50-66, set./dez. 1999.

13. VALLADARES NETO, J. et al. Retardo eruptivo de incisivo permanente associado à retenção prolongada do predecesor decíduo: obstrutivo, traumático, desenvolvimental ou idiopático? Distribuição através de um caso clínico. ROBRAC, Goiânia, v. 5 , n. 15 , p. $4-10,1995$.

\section{Endereço para correspondência}

Walter Leal de Moura

R. São Pedro, 3.274 / 902 - Ilhotas

64001-260 - Teresina - PI

centroface@uol.com.br 